\title{
STRATEGI PENGELOLAAN HUTAN KOTA WADUK SUNTER UTARA DALAM RANGKA MEMPERTAHANKAN FUNGSI WADUK SEBAGAI RESAPAN AIR
}

\author{
Sri Rahayu Maykewati ${ }^{1}$ \\ ${ }^{I}$ Dinas Kehutanan Provinsi DKI Jakarta \\ Email:sri.maykewati@gmail.com
}

\begin{abstract}
Forest of North Sunter Reservoir is one of the urban forest that has been determined by Decree of Jakarta Governor No.317 Year 1999 about Sunter North Road Forest Size Establishment $+2,2$ ha as jungle city forest in North Jakarta Municipality. This study aims to find out how the strategy of Forest Management of North Sunter Reservoir City that can be applied, how the role of stakeholders in management, internal and external factors what, what solution has been done and how the success and what the future expectation. The method used is descriptive qualitative approach. Data collection techniques and procedures used are: (1) Observation; (2) Interviews; (3) Documents; (4) FGD (Focus Group Discussion). The analysis was conducted using environmental analysis, stakeholder analysis, SWOT analysis (Strength Weakness Opportunity Treath) and QSPM (Quantitative Strategic Planning Matrix) analysis.The North Sunter City Forest Management Strategy can be implemented with the collaboration of relevant stakeholders, it is expected to increase the benefit value of its strengths and opportunities, and can minimize the value of weaknesses and threats, so that the North Sunter Reservoir Forest can function optimally and can maintain the function of the reservoir water infiltration.
\end{abstract}

Keywords : Management Strategy, Urban Forest, North Sunter Reservoir, Function of reservoir as water absorption 


\section{PENDAHULUAN}

Provinsi DKI Jakarta sebagai ibukota Negara Republik Indonesia yang merupakan pusat pemerintahan, perekonomian, perdagangan, industri, pusat bisnis, politik, pariwisata, pemukiman, transportasi dan lain-lain sangat padat penduduknya akibat tingginya arus urbanisasi. DKI Jakarta sebagai Kota metropolitan mempuyai daya tarik tersendiri sehingga banyak orang yang berdatangan untuk mengadu nasib di Jakarta. Padatnya jumlah penduduk di DKI Jakarta mengakibatkan kebutuhan akan tempat tinggal, transportasi, sarana dan prasarana sangat tinggi.

Konsekuensinya kota sebagai pusat pertumbuhan antara lain berupa meningkatnya aktivitas transportasi dan pembangunan, yang lebih menekankan pada pembangunan fisik dan ekonomi yang memberikan keuntungan jangka pendek.

Lingkungan Jakarta berkembang secara fisik dan ekonomi tetapi menurun secara ekologis. Hal ini dapat dilihat dari alih fungsi lahan untuk permukiman, pusat-pusat kegiatan kota, transportasi dan industri mengakibatkan makin minimnya kawasan hijau perkotaan atau kawasan resapan. Dengan demikian penggunaan lahan untuk ruang terbuka hijau dan resapan air semakin sangat terbatas.

Hal tersebut di atas menimbulkan dampak negatif yaitu banjir, kekeringan, suhu udara yang semakin panas, polusi, amblesan, erosi, berkurangnya kawasan konservasi dan budidaya, berkurangnya keanekaragaman hayati, menurunnya kualitas air tanah dan terbatasnya ketersediaan air bersih, intrusi air laut serta pendangkalan danau dan sungai. Pada kondisi seperti ini diperlukan pengelolaan ruang terbuka hijau (RTH) untuk memperbaiki kualitas lingkungan kota.

Jumlah penduduk perkotaan yang terus meningkat dari waktu ke waktu tersebut memberikan implikasi pada tingginya pemanfaatan ruang kota sehingga penataan ruang kawasan perkotaaan perlu mendapat perhatian khusus, terutama yang terkait dengan penyediaan kawasan hunian, fasilitas umum dan ruang-ruang terbuka publik di perkotaan.

Pengelolaan ruang di perkotaan cenderung mengalami tantangan yang cukup berat. Sementara di sisi lain, daya dukung lingkungan dan sosial 
yang ada mengalami penurunan, sehingga tidak dapat mengimbangi kebutuhan akibat tekanan penduduk.

Masalah pengelolaan ruang terbuka hijau (RTH) dapat menjadi kompleks karena merupakan bagian dari lingkungan kota. Keberadaan ruang terbuka hijau (RTH) pada kawasan perkotaan diamanatkan oleh UndangUndang No.26 tahun 2007 tentang Penataan Ruang. Pada pasal 29 ayat 2 disebutkan bahwa ruang terbuka hijau pada wilayah kota paling sedikit $30 \%$ dari luas wilayah kota.

Pada kawasan perkotaan RTH merupakan salah satu bentuk pemanfaatan fungsi lindung perkotaan. Sedangkan kawasan lindung didefinisikan sebagai wilayah yang ditetapkan dengan fungsi utama melindungi kelestarian lingkungan hidup yang mencakup sumberdaya alam dan sumberdaya buatan.

Hutan kota merupakan salah satu ruang terbuka hijau (RTH) di perkotaan. Hutan kota merupakan salah satu bentuk ruang terbuka hijau yang sangat diperlukan lingkungan perkotaan. Hutan di perkotaan memiliki banyak fungsi, diantaranya untuk mengatur tata air, menyegarkan udara, menurunkan suhu mikro dan mengurangi kebisingan. Karena perannya yang cukup penting dalam menyangga kehidupan, hutan kota merupakan salah satu fasilitas publik yang wajib dimiliki setiap kota.

Banyak kota-kota besar di Indonesia, termasuk DKI Jakarta, belum memiliki hutan kota yang memadai. Berdasarkan Peraturan Pemerintah Republik Indonesia Nomor 63 Tahun 2002, Hutan kota adalah suatu hamparan lahan yang bertumbuhan pohon-pohon yang kompak dan rapat di dalam wilayah perkotaan baik pada tanah negara maupun tanah hak, yang ditetapkan sebagai hutan kota oleh pejabat yang berwenang. Adapun luas minimal hutan kota diatur dalam pasal 8 ayat 2 dan 3 yaitu luas hutan kota dalam suatu hamparan yang kompak paling sedikit 0,25 Ha. Prosentase luas hutan kota paling sedikit $10 \%$ dari wilayah perkotaan dan atau disesuaikan dengan kondisi setempat.

Luas total hutan kota di Jakarta yang telah ditetapkan berdasarkan SK Gubernur mencapai 149,76 ha. Masih terlalu timpang bila dibandingkan dengan luas wilayah DKI Jakarta yakni 66.233 ha. Bila dipersentasekan luasan tersebut hanya sekitar $0,23 \%$. Hutan 
kota di Jakarta tersebar di 15 titik, terdiri dari Jakarta Pusat 1 titik, Jakarta Utara 4 titik, Jakarta Barat 1 titik, Jakarta Timur 6 titik, dan Jakarta
Selatan 2 titik. Adapun hutan kota di DKI Jakarta yang telah ditetapkan Gubernur DKI Jakarta adalah sebagai berikut :

Tabel 1.

Data Hutan Kota yang sudah ditetapkan Gubernur DKI Jakarta di Provinsi DKI Jakarta

\begin{tabular}{|c|c|c|c|}
\hline NO & HUTAN KOTA & WILAYAH & $\begin{array}{c}\text { LUAS } \\
(\mathrm{Ha})\end{array}$ \\
\hline 1 & Hutan Kota Masjid Istiqlal & Jakarta Pusat & 1,08 \\
\hline 2 & $\begin{array}{l}\text { Hutan Kota Waduk/Danau Sunter } \\
\text { Utara }\end{array}$ & Jakarta Utara & 8,20 \\
\hline 3 & Hutan Kota Kanal Banjir Barat & Jakarta Utara & 2,49 \\
\hline 4 & $\begin{array}{l}\text { Hutan Kota Kawasan Berikat } \\
\text { Nusantara Marunda }\end{array}$ & Jakarta Utara & 1,59 \\
\hline 5 & Hutan Kota Kemayoran & Jakarta Utara & 4,60 \\
\hline 6 & Hutan Kota Srengseng & Jakarta Barat & 15,00 \\
\hline 7 & Hutan Kota PT. JIEP Pulogadung & Jakarta Timur & 8,90 \\
\hline 8 & Hutan Kota Dukuh & Jakarta Timur & 0,58 \\
\hline 9 & $\begin{array}{l}\text { Hutan Kota Bumi Perkemahan } \\
\text { Cibubur }\end{array}$ & Jakarta Timur & 27.32 \\
\hline 10 & Hutan Kota Situ Rawa Dongkal & Jakarta Timur & 3.28 \\
\hline 11 & $\begin{array}{l}\text { Hutan Kota Komplek Kopassus } \\
\text { Cijantung }\end{array}$ & Jakarta Timur & 1.75 \\
\hline 12 & Hutan Kota Mabes TNI Cilangkap & Jakarta Timur & 14.43 \\
\hline 13 & $\begin{array}{l}\text { Hutan Kota Komplek Lanud Halim } \\
\text { Perdana Kusuma }\end{array}$ & Jakarta Timur & 3.5 \\
\hline 14 & $\begin{array}{l}\text { Hutan Kota Kampus Universitas } \\
\text { Indonesia }\end{array}$ & Jakarta Selatan & 55.4 \\
\hline \multirow[t]{2}{*}{15} & $\begin{array}{l}\text { Hutan Kota Blok P Walikota Jakarta } \\
\text { Selatan }\end{array}$ & Jakarta Selatan & 1,64 \\
\hline & & & 149,76 \\
\hline
\end{tabular}

Salah satu hutan kota yang ada di DKI Jakarta adalah Hutan Kota Waduk Sunter Utara yang ditetapkan dengan Surat Keputusan Gubernur DKI Jakarta Nomor 317 Tahun 1999 tentang Penetapan Hutan Kota Keliling Waduk Sunter Utara seluas $\pm 8,2 \mathrm{Ha}$ sebagai hutan kota wisata di Kotamadya Jakarta Utara. Pada diktum kedua SK tersebut di atas, pengelolaannya dilaksanakan oleh Dinas Kehutanan DKI Jakarta.
Dasar penetapan hutan kota ini adalah Surat Kepala Dinas Kehutanan DKI Jakarta Nomor 709/1.823 Tanggal 17 Mei 1994 perihal Batasan dan Kriteria Hutan Kota; dan Surat Sekretaris Badan Pengawas Pelaksanaan Lingkungan Sunter DKI Jakarta Nomor 1391/D/07.73 tanggal 12 September 1997 perihal persetujuan pemakaian jalur hijau sebagai hutan kota. 
Secara geografis Hutan Kota Waduk

Sunter Utara terletak pada 6051'23"

LS dan 106054'39" BT. Berdasarkan

wilayah administrasi pemerintahannya

lokasi hutan kota ini berada di RW 08

Kelurahan Papanggo Kecamatan

Tanjung Priok Kota Administrasi

Jakarta Utara, yang mengelilingi

Waduk Sunter Utara yang sering

disebut oleh masyarakat sekitar Danau

Cincin.

Danau Cincin seluas \pm 32 ha telah ada sejak dahulu dan dikelilingi oleh jalur hijau yang sebag/ian masih berupa semak belukar. Kemudian Jalur hijau tersebut ditetapkan sebagai hutan kota dengan SK Gubernur DKI Jakarta Nomor 317 Tahun 1999.

Dengan adanya hutan kota ini diharapkan dapat menjaga kualitas lingkungan hidup, paru-paru kota, menjaga iklim mikro, menurunkan suhu, konservasi tanah dan air, keanekaragaman hayati, mencegah erosi dan pengendali intrusi air laut, pelindung Waduk Sunter Utara sebagai tangkapan dan resapan air sehingga dapat mengurangi banjir yang sering terjadi di wilayah Jakarta Utara.

Sesuai tujuannya penyelenggaraan hutan kota lebih ditekankan pada fungsinya yaitu untuk memperbaiki dan menjaga iklim mikro, konservasi tanah dan air, nilai estetika, meresapkan air, menciptakan keseimbangan dan keserasian lingkungan fisik kota serta mendukung pelestarian keanekaragaman hayati.

Tujuan penyelenggaraan hutan kota adalah untuk kelestarian, keserasian dan keseimbangan ekosistem perkotaan yang meliputi unsur lingkungan hidup, sosial dan budaya.

Kota Jakarta Utara merupakan wilayah dataran rendah di Provinsi DKI Jakarta, sehingga wilayah ini sering dilanda banjir pada musim hujan. Pada saat musim hujan diharapkan hutan kota dan Waduk Sunter Utara dapat berfungsi sebagai resapan dan tangkapan air hujan, air laut pasang serta air kiriman dari Bogor, sehingga dapat mengurangi banjir di wilayah Jakarta Utara.

Hutan Kota Waduk Sunter Utara terletak di sekeliling Waduk Sunter Utara, sehingga terdapat dua ekosistem yang saling berkaitan yaitu ekosistem hutan kota dan waduk. Hutan kota terdiri dari berbagai flora dan fauna. Vegetasi hutan sudah terbentuk dengan jumlah \pm 3.100 pohon dan jenis pohon 
diantaranya adalah trembesi, ketapang, flamboyan, karet kebo, sawo kecik, tanjung, sapu tangan, sukun, mahoni, salam, johar, kenari, eucalyptus, bintaro, spatudea, nyamplung, buni, angsana, mangga, kayu putih, palm, kemiri, kapuk, jati, nyiur, asam kranji, asam, kenari, glodokan tiang, beringin, bungur dan lain-lain. Jenis fauna yang ditemui adalah berbagai jenis burung (emprit, prenjak, bondol dan kutilang), kupu-kupu, belalang, ular, kadal, capung, lalat, myamuk, tikus, kalelawar, kaki seribu, kalajengking, ulat, semut, kecoa dan lain-lain.

Hutan kota ini berfungsi sebagai kawasan penyangga lingkungan pemukiman, paru-paru kota, menyerap gas polutan, konservasi tanah dan air, pengendali intrusi air laut, pelindung waduk/ danau, menurunkan suhu mikro, mengurangi kebisingan, keanekaragaman hayati, sangtuari satwa, koleksi pelestarian plasma nutfah dan wahana olah raga dan pemancingan.

Pola pemanfaatan lahan oleh masyarakat sekitar belum sepenuhnya dapat mendukung kelestarian lingkungan hidup di hutan kota maupun danau, masih dijumpai adanya sampah di area hutan kota, adanya gubug/ bedeng liar pemulung, warung, tempat penggembalaan kambing, tempat beternak unggas dan aduan burung, pendangkalan danau serta masih terdapatnya lahan kosong di hutan kota yang belum dimanfaatkan untuk penghijauan.

Penggunaan lahan untuk gubug/ bedeng liar dilakukan oleh masyarakat sekitar dan sebagian adalah para pendatang dari daerah lain, mereka mengadu nasib di Jakarta dengan memanfaatkan lahan-lahan yang mereka anggap tidak bertuan. Aktivitas mereka diantaranya adalah sebagai pemulung, pedagang rokok, makanan dan minuman, penggembala kambing, peternak unggas dan pengadu burung di area hutan kota.

Selain itu waduk juga mengalami pendangkalan oleh lumpur dan sampah. Sampah tersebut berasal dari warga sekitar yang membuangnya ke waduk dan hutan kota maupun sampah yang terbawa air laut pasang. Pengerukan waduk seharusnya dilakukan secara rutin dan terjadwal agar waduk dapat berfungsi sebagai area tangkapan dan resapan air.

Hal tersebut di atas menimbulkan berkurangnya tutupan lahan oleh 
pepohonan,

berkurangnya

keanekaragaman

hayati

dan

pendangkalan waduk sehingga

menimbulkan terjadinya banjir dan

erosi pada musim hujan. Erosi

permukaan tanah berakibat pada

tingginya tingkat sedimentasi di

Waduk Sunter Utara, tingginya

sedimentasi ini berpengaruh terhadap

umur waduk dan fungsinya sebagai

area tangkapan dan resapan air.

Hutan kota di DKI Jakarta dikelola oleh Dinas Kehutanan Provinsi DKI Jakarta dan Suku Dinas Kehutanan Kota Administrasi Jakarta Utara agar dapat mempertahankan fungsi dan meningkatkan kualitas hutan kota yang ada. Untuk itu diperlukan suatu kebijakan atau strategi pengelolaan hutan kota agar diperoleh fungsi dan manfaat hutan kota bagi kehidupan manusia perkotaan secara berkelanjutan

\section{METODOLOGI}

Penelitian mengenai pengelolaan hutan kota ini menggunakan pendekatan kualitatif deskriptif. Penelitian ini dilakukan dengan mengumpulkan berbagai informasi terkait topik penelitian dari berbagai sumber, kemudian menganalisisnya untuk dapat menjelaskan fenomena yang terjadi.

Penelitian ini mendeskripsikan secara sistematis, faktual dan akurat terhadap suatu populasi atau daerah tertentu mengenai berbagai sifat dan faktor tertentu, dengan melalui survei lapangan. Informasi yang dikumpulkan dengan menggunakan observasi/ pengamatan lapangan, daftar pertanyaan/ kuesioner, wawancara mendalam dengan pengelola dan pihak terkait serta penelaahan dokumen dari berbagai sumber.

Penelitian kualitatif menjadikan peneliti sendiri sebagai instrumen penelitian untuk mengumpulkan data atau informasi. Peneliti harus luwes dan mampu membuat atau memberikan pandangan sendiri atas hal-hal atau fenomena-fenomena yang dilihatnya.

Penelitian ini dilaksanakan untuk memperoleh fakta-fakta dari gejalagejala yang ada dan mencari keterangan-keterangan secara faktual tentang pola pemanfaatan lahan, pengelolaan hutan kota, kebijakan dan peran institusi serta pemanfaatan hutan kota dan waduknya. Dalam penelitian ini juga dilakukan evaluasi dan 
perbandingan-perbandingan terhadap hal-hal yang telah dilaksanakan oleh pihak lain dalam menangani situasi atau masalah serupa yang dapat digunakan untuk pembuatan rencana dan pengambilan keputusan di masa yang akan datang.
Penelitian di Hutan Kota Waduk Sunter Utara dibatasi pada fase strategi pengelolaan hutan kota dan fungsi waduk sebagai resapan air yang berimplikasi pada aspek lingkungan, sosial dan ekonomi. Adapun alur penelitiannya adalah sebagai berikut:

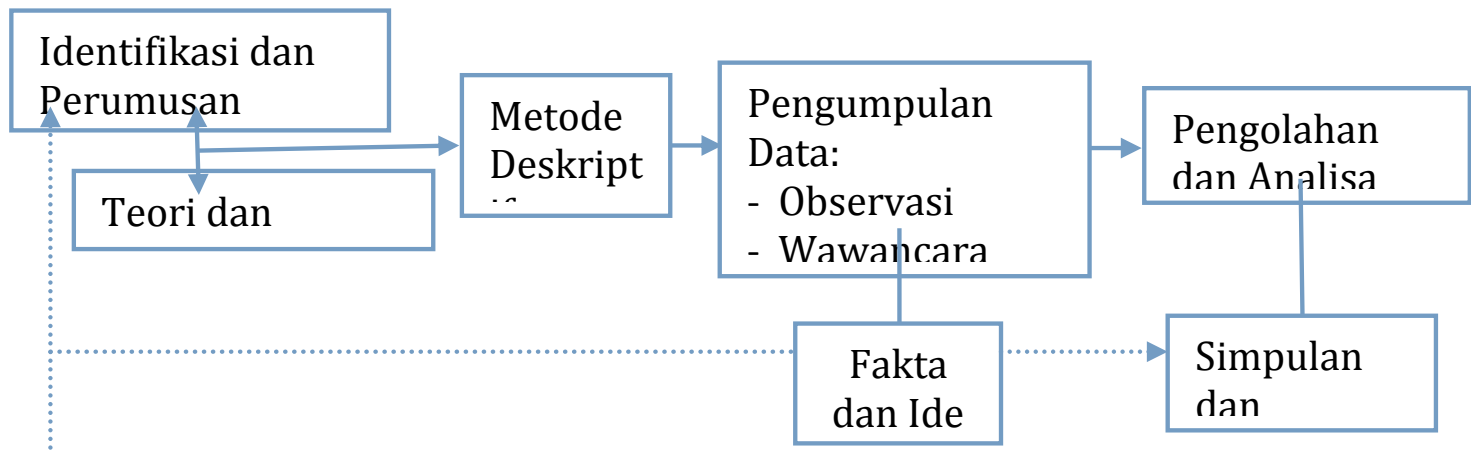

Gambar .1. Alur Penelitian

Pada penelitian ini dikumpulkan data yang bersumber dari data primer dan data sekunder, baik informan, peristiwa maupun dokumen. Data primer didapatkan dari hasil wawancara, kuesioner dan hasil observasi di lapangan. Data sekunder berasal dari sumber-sumber data, seperti monografi wilayah dari BPS dan data-data pendukung dari Dinas Kehutanan Provinsi DKI Jakarta, Suku Dinas Kehutanan Kota Administrasi Jakarta Utara, Suku Dinas Lingkungan Hidup Kota Administrasi Jakarta Utara, Suku Dinas Pekerjaan Umum Kota Administrasi Jakarta Utara, Suku Dinas Sumberdaya Air Kota
Administrasi Jakarta Utara, Kecamatan Tg.Priok dan Kelurahan Papanggo.

Teknik dan prosedur pengumpulan data yang digunakan adalah : (1). Observasi yaitu pengamatan langsung di Hutan Kota Waduk Sunter Utara, Waduk Sunter Utara dan lingkungan sekitarnya; (2). Wawancara yaitu tanya jawab dengan menggunakan daftar pertanyaan, dilakukan terhadap aparat di tingkat provinsi, tingkat kota, tingkat kecamatan sampai tingkat kelurahan, CSR (Corporate Social Responsibility), tokoh masyarakat, pengunjung dan masyarakat sekitar Hutan Kota Waduk Sunter Utara; (3). Dokumen: mempelajari dokumen- 
dokumen yang berhubungan dengan pengelolaan Hutan Kota Waduk Sunter Utara; (4). FGD (Focus Group Discussion): berdiskusi dengan pihakpihak yang berhubungan langsung dengan pengelolaan Hutan Kota Waduk Sunter Utara.

\section{Hasil Penelitian dan Pembahasan}

Berdasarkan masalah, maka hasil penelitian ini dilakukan dengan menginterpretasikan melalui deskripsi data dan analisisnya adalah sebagai berikut:

\section{Identifikasi dan Analisis}

\section{Lingkungan}

Analisis lingkungan berfungsi untuk memahami kondisi internal dan eksternal terkait pengelolaan Hutan Kota Waduk Sunter Utara. Pemahaman mendalam terhadap kondisi tersebut dapat digunakan sebagai cara untuk mengidentifikasi semua fakkor internal (kekuatan dan kelemahan) dan faktor eksternal (peluang dan ancaman).
Berdasarkan hasil identifikasi, kemudian dilakukan analisis terhadap kondisi internal dan eksternal Hutan Kota Waduk Sunter Utara saat ini. Analisis tersebut merupakan bentuk evaluasi terhadap masing-masing faktor. Analisis dilakukan dengan melakukan pembobotan, penentuan rating dan skor akhir penilaian terhadap masing-masing faktor internal dan eksternal Hutan Kota Waduk Sunter Utara. Hasil evaluasi faktor internal dapat dilihat pada Tabel 2 .

Evaluasi Faktor Internal (EFI) menunjukkan nlai 1,90, dapat dikatakan bahwa pengelolaan Hutan Kota Waduk Sunter Utara sampai saat ini belum optimal.atas berbagai kekuatan yang dimilikinya dan sangat dipengaruhi oleh berbagai kelemahan yang dipunyainya. Kelemahan masih dominan dalam menentukan kondisi terkini Hutan Kota Waduk Sunter Utara yang berpengaruh terhadap kondisi hutan kota.yang menurun.

Tabel 2.

Evaluasi Faktor Internal (EFI) Hutan Kota Waduk Sunter Utara

\begin{tabular}{|l|c|c|c|}
\hline \multicolumn{1}{|c|}{ Faktor Internal } & Bobot & Skor & Bobot x Skor \\
\hline Kekuatan & 0,15 & 4 & 0,60 \\
1. Kejelasan Status & 0,15 & 3 & 0,45 \\
2. Kejelasan Pengelola & 0,15 & 2 & 0,30 \\
3. Vegetasi hutan sebagian sudah & & & \\
\hline
\end{tabular}




\begin{tabular}{|l|l|l|l|}
\hline Kelemahan & & & \\
1. Banjir pada musim penghujan & 0,15 & 1 & 0,15 \\
2. Adanya perambah & 0,20 & 1 & 0,20 \\
3. Minimnya sarana dan prasarana & 0,20 & 1 & 0,20 \\
$\quad$ bagi pengunjung & & & \\
\hline \multicolumn{1}{|c|}{ Total } & 1,00 & & $\mathbf{1 , 9 0}$ \\
\hline
\end{tabular}

Hasil evaluasi terhadap faktor eksternal (EFE) dapat dilihat pada Tabel 3 berikut :

Tabel. 3.

Evaluasi Faktor Eksternal (EFE) Hutan Kota Waduk Sunter Utara

\begin{tabular}{|l|c|c|c|}
\hline \multicolumn{1}{|c|}{ Faktor Eksternal } & Bobot & Skor & Bobot x Skor \\
\hline $\begin{array}{l}\text { Peluang } \\
\text { 1. Komitmen Pemprov DKI Jakarta }\end{array}$ & 0,15 & 4 & 0,60 \\
$\begin{array}{l}\text { 2. Kawasan konservasi dan } \\
\text { berpotensi sbg ekowisata }\end{array}$ & 0,15 & 3 & 0,45 \\
3. Kebutuhan masyarakat & 0,15 & 2 & 0,30 \\
\hline $\begin{array}{l}\text { Ancaman } \\
\text { 1. Pencemaran hutan kota dan } \\
\quad \text { waduk }\end{array}$ & 0,20 & 1 & 0,20 \\
$\begin{array}{l}\text { 2. Penurunan tanah dan rob } \\
\text { 3. Rendahnya kesadaran masyarakat }\end{array}$ & 0,15 & 1 & 0,15 \\
\hline \multicolumn{1}{|c|}{ Total } & 1,00 & 1 & 0,20 \\
\hline
\end{tabular}

Analisis lingkungan eksternal mengidentifikasikan peluang dan ancaman Hutan Kota Waduk Sunter Utara. Evaluasi faktor eksternal menunjukkan nilai 2,45. Berdasarkan nilai tersebut dapat dikatakan bahwa Hutan Kota Waduk Sunter Utara belum memperoleh manfaat optimal dan peluang dan sangat rentan terhadap ancaman yang dihadapinya.

\section{Analisis Stakeholder}

Berdasarkan hasil identifikasi menunjukkan bahwa stakeholder Hutan Kota Waduk Sunter Utara terdiri dari unsur Pemerintah yaitu
Kementerian Lingkungan Hidup dan Kehutanan, Pemerintah Provinsi DKI Jakarta; pihak swasta; akademisi; Lembaga Swadaya Masyarakat (LSM) dan masyarakat yang mempunyai peran dan kepentingan berbeda-beda, sebagaimana tertuang pada Tabel 4 .

Keterlibatan stakeholder dalam pengelolaan hutan kota didasarkan atas pengaruh dan kepentingan yang berbeda-beda. Perbedaan tersebut berhubungan dengan kapasitas, kewenangan dan minat. Adanya perbedaan pengaruh dan kepentingan berdampak pada perbedaan peran 
masing-masing stakeholder dalam pengelolaan hutan kota.

Pengaruh merupakan kemampuan stakeholder untuk mempengaruhi proses pengelolaan hutan kota dan kemampuannya mempengaruhi stakeholder lain.
Kepentingan dapat diartikan sebagai ketergantungan stakeholder terhadap sumberdaya atau ketertarikan untuk terlibat dalam pengelolaan hutan kota. Tingkat kepentingan dan pengaruh stakeholder ditunjukkan dalam skor $1-5$ sebagaimana tertuang pada Tabel 5.

Tabel. 4.

\begin{tabular}{|c|c|c|}
\hline Stakeholder & Peran & Kepentingan \\
\hline $\begin{array}{l}\text { Pemerintah } \\
\text { - Kementerian Lingkungan } \\
\text { Hidup dan Kehutanan } \\
\text { - Kementerian PU }\end{array}$ & $\begin{array}{l}\text { Regulasi dan } \\
\text { koordinasi }\end{array}$ & $\begin{array}{l}\text { Legalitas hutan kota } \\
\text { (Peraturan Pemerintah } \\
\text { No.63 tahun 2002). } \\
\text { Legalitas waduk. }\end{array}$ \\
\hline $\begin{array}{l}\text { Pemprov. DKI Jakarta : } \\
\text { - Dinas Kehutanan dan } \\
\text { Sudin } \\
\text { - Dinas Lingkungan Hidup } \\
\text { dan Sudin } \\
\text { - Dinas Sumberdaya Air } \\
\text { dan Sudin }\end{array}$ & $\begin{array}{l}\text { Pengelola hutan kota } \\
\text { Pengelola } \\
\text { kebersihan } \\
\text { Pengelola danau }\end{array}$ & $\begin{array}{l}\text { Memelihara hutan kota } \\
\text { agar terjaga fungsinya. } \\
\text { Bertanggung jawab } \\
\text {.terhadap sampah. } \\
\text { Memelihara danau agar } \\
\text { berfungsi. }\end{array}$ \\
\hline $\begin{array}{l}\text { Swasta : } \\
\text { - PT. Adhi Karya } \\
\text { - Hutama Karya } \\
\text { - Jaya Konstruksi } \\
\text { - PT. Jakon Adhi }\end{array}$ & $\begin{array}{l}\text { Pelaksana } \\
\text { kompensasi } \\
\text { Pelaksana } \\
\text { kompensasi } \\
\text { Pelaksana } \\
\text { kompensasi } \\
\text { Pelaksana } \\
\text { kompensasi }\end{array}$ & $\begin{array}{l}\text { Penurapan tepi danau } \\
\text { Penurapan tepi danau } \\
\text { Penurapan tepi danau }\end{array}$ \\
\hline Akademisi & Peneliti & $\begin{array}{l}\text { Pengembangan wawasan } \\
\text { dan ilmu }\end{array}$ \\
\hline Masyarakat & Penerima dampak & $\begin{array}{l}\text { Memperoleh daya dukung } \\
\text { lingkungan }\end{array}$ \\
\hline LSM & Mediator & Citra positif \\
\hline
\end{tabular}


Tabel 5. Kepentingan dan Pengaruh Stakeholder pada Pengelolaan Hutan Kota Waduk Sunter Utara

\begin{tabular}{|l|c|c|}
\hline \multicolumn{1}{|c|}{ Stakeholder } & Skor Pengaruh & $\begin{array}{c}\text { Skor } \\
\text { Kepentingan }\end{array}$ \\
\hline $\begin{array}{l}\text { Pemerintah } \\
\text { - Kementerian Lingkungan Hidup dan }\end{array}$ & 4 & 3 \\
$\quad$ Kehutanan & 3 & 2 \\
- Kementerian PU & 5 & 5 \\
\hline Pemprov. DKI Jakarta: & 4 & 3 \\
- Dinas Kehutanan dan Sudin & 4 & 3 \\
- Dinas Lingkungan Hidup dan Sudin & & 3 \\
- Dinas PU Tata Air dan Sudin & 2 & 3 \\
\hline Swasta/ CSR: & 2 & 3 \\
- PT. Adhi Karya & 2 & 3 \\
- Hutama Karya & 1 & 3 \\
- Jaya Konstruksi & 4 & 2 \\
\hline Akademisi & 2 & \\
\hline Masyarakat & & \\
\hline LSM & & \\
\hline
\end{tabular}

3. Analisis SWOT (Strength

\section{Weakness Opportunity Treath)}

Formulasi strategi adalah langkah penyusunan alternatif strategi pengelolaan hutan kota. Pada tahap ini dilakukan pencocokan terhadap faktor internal dan eksternal dengan menggunakan matrik SWOT untuk menentukan strategi yang tepat.
Perumusan strategi menghasilkan 4 (empat) alternatif yaitu Strategi Strength-Opportunity (Strategi SO), Strategi Strength-Treath (Strategi ST), Strategi Weakness-Opportunity (Strategi WO), Strategi Weakness Treath (Strategi WT), seperti tertuang pada Tabel 6 di bawah ini :

Tabel. 6.

Matrik SWOT Pengelolaan Hutan Kota Waduk Sunter Utara

\begin{tabular}{|l|l|l|}
\hline Faktor Eksternal & $\begin{array}{l}\text { Peluang }(O): \\
\text { 1. Komitmen tinggi } \\
\text { Pemprov DKI } \\
\text { Jakarta }\end{array}$ \\
$\begin{array}{l}\text { 2. } \begin{array}{l}\text { Minat tinggi } \\
\text { stakeholder }\end{array} \\
\text { Faktor Internal }\end{array}$ & $\begin{array}{l}\text { 1. Pencemaran hutan } \\
\text { 2. Penuruan dan danau dan } \\
\text { rob }\end{array}$ \\
\hline
\end{tabular}




\begin{tabular}{|c|c|c|}
\hline & & masy. \\
\hline $\begin{array}{l}\text { Kekuatan }(S) \text { : } \\
\text { 1. Kejelasan Status } \\
\text { 2. Kejelasan Pengelola } \\
\text { 3. Vegetasi hutan sudah } \\
\text { terbentuk }\end{array}$ & $\begin{array}{l}\text { Strategi SO : } \\
\text { 1. Sosialisasi eksistensi } \\
\text { hutan kota } \\
\text { 2. Kolaborasi } \\
\text { pengelolaan }\end{array}$ & $\begin{array}{l}\text { Strategi ST : } \\
\text { 1. Pemetaan zonasi } \\
\text { pengelolaan } \\
\text { 2. Pendidikan } \\
\text { lingkungan }\end{array}$ \\
\hline $\begin{array}{l}\text { Kelemahan }(W) \text { : } \\
\text { 1. Banjir pada musim } \\
\text { penghujan } \\
\text { 2. Adanya penggarap } \\
\text { liar } \\
\text { 3. Implementasi } \\
\text { pengelola belum } \\
\text { optimal }\end{array}$ & $\begin{array}{l}\text { Strategi WO : } \\
\text { 1. Perlindungan } \\
\text { ekosistem } \\
\text { 2. Kolaborasi } \\
\text { pengelolaan } \\
\text { 3. Penegakan hukum }\end{array}$ & $\begin{array}{ll}\text { Strategi WT : } \\
\text { 1. } & \text { Rehabilitasi } \\
& \text { ekosistem } \\
\text { 2. } & \text { Pengamanan hutan } \\
& \text { kota dan penegakan } \\
& \text { hukum }\end{array}$ \\
\hline
\end{tabular}

4. Analisis QSPM (Quantitative Strategic Planning Matrix)

Pengambilan keputusan adalah tahap pemilihan strategi prioritas dengan menggunakan teknik QSPM. Teknik ini mendasarkan pada penilaian skor kemenarikan relatif tiap strategi terhadap faktor internal dan eksternal hutan kota. Skor hasil penilaian kemudian dijumlahkan sehingga masing-masing strategi mempunyai skor total dengan besaran tertentu. Strategi dengan skor tertinggi menjadi prioritas utama. Berdasarkan penilaian QSPM strategi pengelolaan hutan kota dapat diurutkan sesuai prioritas sebagaimana Tabel 7.

Tabel .7.

Strategi Prioritas Pengelolaan Hutan Kota Waduk Sunter Utara

\begin{tabular}{|l|c|c|l|}
\hline \multicolumn{1}{|c|}{ Alternatif Strategi } & $\begin{array}{c}\text { Skor } \\
\text { QSPM }\end{array}$ & $\begin{array}{c}\text { Prioritas } \\
\text { ke- }\end{array}$ & \multicolumn{1}{|c|}{$\begin{array}{c}\text { Stakeholder yang } \\
\text { terlibat }\end{array}$} \\
\hline Rehabilitasi ekosistem & 7,3 & 1 & $\begin{array}{l}\text { Dinas Kehutanan, } \\
\text { Swasta/ CSR }\end{array}$ \\
\hline Kolaborasi pengelolaan & 7,1 & 2 & Semua Stakeholder \\
\hline Perlindungan ekosistem & 7,0 & 3 & $\begin{array}{l}\text { Kementerian LHK, } \\
\text { Dinas Kehutanan, } \\
\text { Dinas Lingkungan } \\
\text { Hidup, Swasta/ CSR }\end{array}$ \\
\hline $\begin{array}{l}\text { Sosialisasi eksistensi hutan } \\
\text { kota }\end{array}$ & 6,8 & 4 & Dinas Kehutanan \\
\hline $\begin{array}{l}\text { Pendidikan lingkungan } \\
\text { Pengamanan hutan kota dan } \\
\text { penegakan hokum }\end{array}$ & 5,9 & 5 & $\begin{array}{l}\text { Dinas Kehutanan dan } \\
\text { masyarakat }\end{array}$ \\
\hline
\end{tabular}




\begin{tabular}{l|l}
5,5 & 7 \\
\hline
\end{tabular}

Dinas Kehutanan

1. Pengelolaan Hutan Kota Waduk Sunter Utara

Hutan Kota Waduk Sunter Utara merupakan salah satu hutan kota di Jakarta Utara seluas \pm 8,2 Ha yang mengelilingi Waduk Sunter Utara, dikelola oleh Dinas Kehutanan Provinsi DKI Jakarta.

Hutan kota ini sangat besar manfaatnya bagi kelangsungan makhluk hidup, terutama manusia, salah satu manfaatanya adalah mengambil Karbondioksida $\left(\mathrm{CO}_{2}\right)$ dan menggantinya dengan Oksigen $\left(\mathrm{O}_{2}\right)$ yang diperlukan manusia, maka sering disebut sebagai paru-paru kota. Selain itu hutan kota ini juga sebagai penampung air hujan dalam tanah, mengatur tata air tanah, mencegah erosi, mempertahankan kesuburan tanah dan melestarikan keanekaragaman hayati, (manfaat klimatologis, hidrologis dan ekologis).

Pengelolaan hutan kota ini meliputi perencanaan, pengorganisasian, pelaksanaan, pengawasan dan pengendalian. Perencanaan terdiri dari penataan area, pembagian area, rencana kegiatan dan anggaran, penyediaan tenaga kerja dan sarana prasaranya.

Pengorganisasian adalah penyusunan struktur organisasi sesuai dengan sumber dan lingkungannya untuk mencapai tujuan. Dinas Kehutanan Provinsi DKI Jakarta di tingkat kota adalah Suku Dinas Kehutanan Kota Administrasi Jakarta Utara. Pelaksanaan kegiatan hutan kota diserahkan ke Suku Dinas Kehutanan Kota Administrasi Jakarta Utara.

Pelaksanaan kegiatan terdiri dari penanaman, penyulaman tanaman dan pemeliharaan pohon (pendangiran, penyiraman, pemupukan, penopingan, pembabatan semak belukar). Pelaksanaan kegiatan ini secara rutin dilaksanakan oleh tenaga kerja kontrak (PJLP) yang diawasi oleh PNS Suku Dinas Kehutanan Kota Administrasi Jakarta Utara.

Dalam pelaksanaaan ini juga melibatkan stakeholder yang lain yaitu Dinas Lingkungan Hidup yang bertanggung jawab terhadap sampah yang ada, Dinas Pekerjaan Umum Tata 
Air yang bertanggung jawab terhadap danau dan pihak dan kelurahan yang ikut serta menjaga keamanan hutan kota.

Keterlibatan swasta dan CSR dalam penanaman pohon di hutan kota sangat mendukung program pemerintah dalam penghijauan. Pada tahun 2016 dilaksanakan penurapan pinggir danau oleh Kementerian Pekerjaan Umum, akibat pekerjaan tersebut \pm 1.286 pohon di hutan kota ditebang. Pihak ketiga yang melaksanakan pekerjaan tersebut mengganti pohon yang ditebang dengan menanam dan memelihara pohon di pinggir danau sebanyak \pm 3.970 pohon.

Keterlibatan masyarakat sekitar sangat berpengaruh terhadap kelestarian hutan kota. Jika masyarakat tidak membuang sampah, tidak menggembala kambing dan tidak mendirikan gubuk liar di area hutan kota maka hutan kota akan lestari.

Sampah yang ada memancing orang untuk membuang sampah di tempat tersebut, sehingga sampah yang ada harus segera dibersihkan. Penggembalaan kambing mengakibatkan pohon-pohon yang baru ditanam gagal tumbuh karena habis dimakan kambing. Gubuk liar yang ada membuat hutan kota menjadi kumuh dan tidak tertata. Pendangkalan danau akibat lumpur yang tidak pernah dikeruk menyebabkan hutan kota banjir pada musim penghujan karena daya tamping danau tidak maksimal.

Masyarakat perlu diberikan pemahaman dan pengertian secara persuasif agar turut serta menjaga hutan kota. Pendiidkan lingkungan dan penyuluhan kepada masyarakat juga dapat merubah perilaku atau kebiasaan yang tidak baik.

Kerjasama dengan pihak terkait untuk kebersihan hutan kota, pembongkoran gubuk liar, merelokasi tempat penggembalaan kambing dan pengerukan lumpur di danau harus dilakukan agar terwujud hutan kota tertata dan terpelihara.

Pelaksanaan kegiatan secara keseluruhan diawasi oleh Dinas Kehutanan Provinsi DKI Jakarta dan Inspektorat Kota Administrasi Jakarta Utara. Pengawasan ini dilakukan secara berkala agar terpantau pelaksanaan kegiatannya dan dicapai hasil pekerjaan yang optimal. Pengawasan ini merupakan upaya pengedalian pengelolaan hutan kota sehingga dapat meningkatkan kualitas 
hutan kota dan dapat mempertahankan fungsi danau sebagai resapan air.

\section{Strategi Pengelolaan Hutan}

\section{Kota Waduk Sunter Utara}

Berdasarkan data dan hasil analisa, maka Hutan Kota Waduk Sunter Utara dapat dikelola melalui strategi pengeloaan dengan urutan prioritas sebagai berikut:

\section{a. Rehabilitasi ekosistem}

Permendagri 61 tahun 2010 mendefinisikan rehabilitasi ekosistem adalah upaya untuk memulihkan, mempertahankan dan meningkatkan fungsi hutan dan lahan sehingga daya dukung, produktivitas dan peranannya dalam mendukung sistem penyangga kehidupan tetap terjaga. Rehabilitasi perlu dilakukan mengingat ekosistem hutan kota banyak mengalami gangguan berupa pencemaran, sampah dan adanya penggarap liar.

Ekosistem hutan kota dipengaruhi ekosistem darat dan danau. Ekosistem darat berpengaruh melalui pola drainase dan resapan air ke dalam tanah. Ekosistem danau berpengaruh dalam bentuk drainase, daya tampung air hujan dan pasang surut air laut. Pengaruh ekosistem darat dapat terlihat dari kondisi DAS yang memasok air tawar dan muatan sedimen. Hutan Kota menerima pengaruh dari DAS Ciliwung, kekritisan lahan di bagian hulu DAS berpengaruh kepada ekosistem hutan kota.

DAS yang rawan ditandai salah satunya dari tingkat erosi yang tinggi yang menyebabkan sedimentasi di Waduk Sunter Utara. Kegiatan rehabilitasi hutan kota dapat dilakukan secara alami dan atau dengan bantuan manusia yaitu penanaman. Secara alami pohon-pohon yang ada mampu menghasilkan biji yang kemudian jatuh krn terbawa angin atau dibawa burung. Rehabilitasi dengan menanam pohon pada lahan yang masih kosong, penyulaman (mengganti tanaman yang mati) dan pemeliharaan pohon, tingkat keberhasilan tumbuhnya lebih tinggi daripada secara alami.

Rehabilitasi sebaiknya menggunakan jenis asli atau Jenis flora yang ada di hutan kota ini adalah mahoni, trembesi, eucalyptus, salam, bintaro, spatudea, sengon, ketapang, buni, nyamplung, tanjung, kayu putih, sawo kecik, flamboyan dan lain-lain. enis fauna yang dijumpai yaitu burung emprit, prenjak, bondol, kutilang, kadal, tikus, kupu kuning, belalang, kalajengking dan beberapa jenis lainnya. 
Pemulihan fungsi danau dengan upaya pengerukan lumpur danau dan pembersihan sampah secara rutin, diharapkan danau sebagai area tangkapan air yang dapat mengatasi permasalahan banjir.

\section{b. Kolaborasi pengelolaan}

Keterlibatan stakeholder berarti partisipasi dalam perencanaan, pemanfaatan dan pengendalian pemanfaatan hutan kota. Kolaborasi pengelolaan diperlukan agar tercipta sistem dan kelembagaan yang seimbang serta saling mendukung dalam menjaga hutan kota. Seimbang berarti proporsional sesuai dengan kekuatan, peran dan fungsi setiap stakeholder.

Kolaborasi berarti memenuhi dan saling menghormati hak dan kewajiban masing-masing pihak. Hal terpenting dalam kolaborasi adalah kesamaan dalam tujuan. Tujuan yang sama akan mempermudah penyatuan harapan masing-masing pihak dan memberikan arah yang pasti terhadap pengelolaan hutan kota. Langkah selanjutnya terletak pada bagaimana cara mencapai tujuan dan peran apa yang akan dilakukan oleh masing-masing stakeholder dalam pengelolaan hutan kota. Pembagian peran dengan tepat sesuai dengan kapasitas dan kemampuan akan menjamin efektivitas pengelolaan.

Kontribusi setiap stakeholder dapat berbentuk sumberdaya manusia, pendanaan atau anggaran, fasilitas pendukung, data dan informasi atau bentuk-bentuk lain sesuai dengan kesepakatan bersama. Kolaborasi stakeholder dalam pengelolaan hutan kota dapat dilakukan dengan langkah sebagai berikut :

i. Pembentukan kelembagaan kolaborasi.

Kelembagaan kolaborasi mencakup segala hal yang berhubungan dengan hak dan kewajiban masing-masing pihak sesuai dengan peran dan tanggung jawabnya.

ii. Penyusunan rencana kegiatan dalam jangka waktu tertentu.

Tahap ini diperlukan agar setiap langkah yang dilakukan adalah hasil perencanaan dan kesepakatan bersama.

iii. Pelaksanaan kegiatan sesuai dengan perencanaan.

Pada tahap ini dapat diketahui bagaimana proses perencanaan dapat diimplementasikan dan dapat mengatasi permasalahan dan hambatan yang ada.

iv. Monitoring dan evaluasi. 
Kegiatan ini dilakukan setiap periode tertentu sesuai dengan kesepakatan sehingga diketahui pencapaian hasil kolaborasi dalam rangka pengingkatan efektivitas kolaborasi.

\section{c. Perlindungan ekosistem}

Perlindungan merupakan upaya pencegahan dan penanggulangan terhadap kerusakan ekosistem. Perlindungan ekosistem hutan kota secara keseluruhan merupakan langkah perlindungan terhadap danau sehingga secara signifikan dapat memberikan daya dukung optimal terhadap keberadaan hutan kota.

Ekosistem hutan kota harus dilindungi dari erosi, rob, sampah dan pencemaran serta penggunaan lahan yang tidak sesuai peruntukannya. Perlindungan ini dapat dilakukan dengan berkolaborasi dengan stakeholder terkait seperti untuk penggusuran penggarap liar. Setelah penggusuran penanaman pohon harus segera dilakukan agar penggarap liar tidak kembali lagi. Pohon-pohon yang sudah ada harus dipelihara sehingga dapat mencegah erosi dan meresapkan air ke dalam tanah. Selain itu juga dapat melindungi danau dari longsor.

Perlindungan terhap masalah pencemaran dan sampah dilakukan dengan pembersihan sampah secara rutin baik di hutan kota maupun danau. Penanganan sampah harus terus berkoordinasi dan bekerja sama dengan pihak-pihak lain dan masyarakat sekitar. Hal ini dikarenakan sumber sampah tidak hanya dari daerah sekitar tapi juga dari daerah di atasnya. Langkah sederhana yang dapat dilakukan untuk penanggulangan sampah adalah dengan memasang jaring perangkap sampah pada setiap saluran air yang menuju hutan kota dan danau.

Dilihat dari lokasinya yang berada di tengah kota, tidak menutup kemungkinan industri di sekitarnya membuang limbah cair ke saluran yang menimbulkan pencemaran, oleh sebab itu perlu bekerja sama dengan Dinas Lingkungan Hidup untuk menagani hal ini agar kelestarian hutan kota dapat terjaga.

d. Sosialisasi eksistensi hutan kota Hutan Kota Waduk Sunter Utara memiliki potensi penting dalam memberikan daya dukung bagi kehidupan sehingga perlu diperkenalkan secara intensif. Apabila kondisi hutan kota saat ini masih belum sesuai harapan, dimungkinkan salah satu faktornya adalah ketidaktahuan masyarakat tentang 
hutan kota. Apa dan bagaimana peranan penting hutan kota dalam mendukung kehidupan masyarakat sekitar perlu disosialisasikan, mulai dari anak-anak, generasi muda dan generasi tua, baik secara langsung maupun melalui media social, surat kabar, spanduk, pamflet, leaflet, brosur, internet dan media lain.

Keberhasilan sosialisasi ini dapat dilihat dari peningkatan kunjungan masyarakat ke hutan kota, antusiasme partisipasi masyarakat dalam pengelolaan hutan kota dan meningkatnya minat stakeholder terhadap hutan kota.

\section{e. Pendidikan lingkungan}

Pendidikan lingkungan dan penyuluhan merupakan upaya untuk memperbaiki sikap dan perilaku. Pendidikan lingkungan harus dilakukan sedini mungkin, anak-anak sekolah harus dibidik sebagai target dalam pendidikan lingkungan. Fase anak-anak adalah masa perekaman dan pembelajaran yang efektif. Anak-anak sangat mudah menerima masukan dari lingkungan sekitarnya. Masukan positif berupa kesadaran lingkungan akan menjadi modal untuk perubahan besar dalam masyarakat. Pendidikan lingkungan dapat dijadikan muatan lokal pelajaran di sekolah.
Pelaksanaannya bekerja sama dengan Dinas Pendidikan.

Selain itu hutan kota juga dapat dijadikan tempat pembelajaran pengenalan jenis tanaman dan penelitian bagi pelajar dan mahasiswa.

\section{f. Pengamanan hutan kota dan penegakan hukum}

Pengamanan berfungsi untuk mengurangi atau menghilangkan gangguan terhadap hutan kota. Pengamanan hutan kota adalah salah satu komponen dalam perlindungan hutan. Kegiatan pengamanan hutan kota terdiri dari tahapan mulai dari perencanaan, pelaksanaan, pengawasan dan pengendalian.

Pengamanan secara efektif dapat dilakukan dengan pemberdayaan semua pihak, misalnya pembentukan kelompok-kelompok masyarakat, karang taruna dan organisasi massa. Kelompok yang dilibatkan dalam pengamanan adalah mereka yang diperkirakan mendapat manfaat dari keberadaan hutan kota. Dengan demikian akan muncul rasa memiliki dan tanggung jawab terhadap tugasnya. Langkah-langkah persuasif diperlukan agar mampu menggugah kesadaran dan kepedulian masyarakat untuk berpartisipasi dalam pengamanan hutan kota. 
Pengamanan hutan kota harus senantiasa dilakukan pada saat kondisi yang paling aman sekalipun. Prinsip dalam pengamanan hutan adalah bahwa setiap kondisi memiliki peluang yang sama untuk terjadinya pelanggaran terhadap hutan kota. Oleh sebab itu perlu pendanaan regular yang cukup, keterbatasan anggaran menyebabkan kegiatan pengamanan hutan kota tidak optimal, salah satu solusinya dengan pemanfaatan CSR atau bekerja sama dengan pihak swasta.

Penegakan hukum adalah upaya mengawal agar segala sesuatu berjalan sesuai harapan. Penegakan hukum merupakan suatu bentuk punishment terhadap segala pelanggran yang terjadi. Keadilan penegakan hukum akan mendorong terwujudnya tata kehidupan masyarakat yang baik.

Penanganan terhadap penggarap liar sudah pernah dilakukan penggusuran gubuk bekerja sama dengan Satuan Polisi Pamong Praja Kelurahan Papanggo, tetapi beberapa bulan kemudian mereka mendirikan kembali di titik lokasi yang lain. Hal ini terjadi karena kurangnya pengamanan hutan kota secara intensif. Menindaklanjuti hal tersebut di atas maka dilakukan pendekatan persuasif terhadap penggarap liar agar segera membongkar sendiri gubuknya dan berkoordinasi dengan Dinas Kehutanan Provinsi DKI Jakarta agar melaksanakan operasi rutin ke Hutan Kota Waduk Sunter Utara.

\section{g. Pemetaan zonasi pengelolaan}

Upaya mempertahankan dan memulihkan hutan kota harus dibarengi dengan mengatur pembagian zonasi pengelolaan hutan kota, yang terdiri dari blok perlindungan, blok pemanfaatan dan blok dengan tujuan khusus.

Kegiatan yang dilakukan pada blok perlindungan adalah kegiatan pemanfaatan air, pemuliaan tanaman, pengayaan tanaman, penangkaran, penyediaan plasma nutfah, wisata hutan kota, penelitian dan pendidikan.

Pada blok pemanfaatan dapat dilakukan berupa hasil hutan non kayu, jasa lingkungan maupun agroforestry. Agroforestry merupakan perpaduan tanaman pertanian dengan pohon kehutanan, di antara pohon kehutanan yang masih kecil dapat ditanami tanaman hortikultura maupun tanaman obat.

Pemetaan zonasi hutan kota berarti pemetaan untuk penentuan blok pengelolaan. Penentuan atau pembagian blok didasarkan atas hasil inventarisasi potensi hutan, untuk 
memperoleh informasi potensi, penggunaan dan penutupan lahan, jenis tanah, topografi, hidrologi (tata air), karakteristik, bentang alam, jenis dan potensi sebaran flora fauna dan kondisi sosial ekonomi budaya masyarakat.

Hasil inventarisasi tersebut di atas dijadikan dasar dalam pembagian blok yang harus memperhatikan karakteristik biofisik lapangan, potensi sumberdaya alam dan kondisi sosial ekonomi masyarakat.

Kondisi masyarakat sekitar hutan kota perlu diperhatikan dan dijadikan pertimbangan dalam melakukan zonasi hutan kota. Hal ini bertujuan untuk menentukan bagian-bagian dalam hutan kota yang rawan (berpotensi) pelanggaran atau yang relative aman dari gangguan. Keterlibatan partisipasi masyarakat sekitar dalam pengelolaan hutan kota memerlukan penanganan khusus agar dapat dilakukan dengan efektif. Kelembagaan yang berkembang dalam kehidupan sosial masyarakat harus diperhatikan. Kelembagaan masyarakat meliputi norma dan perilaku, peran tokoh agama dan masyarakat, struktur masyarakat, tingkat pendidikan, profesi dan lain-lain.

\section{Implementasi Strategi}

Prioritas strategi berusaha memberikan fokus pengelolaan yang dapat ditempuh dalam jangka pendek untuk menuju tujuan besar selanjutnya. Berbagai alternatif strategi dan prioritasnya bukan menjadi hal baku, tetapi bersifat rekomendasi berdasarkan pertimbangan ilmiah atas kondisi yang dihadapi saat ini.

Pada prakteknya setiap strategi dapat dilakukan secara bersama-sama karena saling keterkaitan satu sama lain. Pertimbangan ilmiah berupa perumusan strategi dimaksudkan untuk memberi solusi atas berbagai keterbatasan dalam pengelolaan Hutan Kota Waduk Sunter Utara.

\section{Kesimpulan}

Berdasarkan hasil pembahasan maka dapat disimpulkan sebagai berikut: 1). Upaya mengelola Hutan Kota Waduk Sunter Utara mulai dari perencanaan, pengorganisasian, pelaksanaan dan pengendalian telah terjadi keterlibatan, kontribusi dan tanggung jawab semua stakeholder, khususnya Dinas Kehutanan Provinsi DKI Jakarta; 2). Hutan Kota Waduk Sunter Utara mendapatkan manfaat dari kekuatan dan peluang yang dimilikinya, sebaliknya kelemahan dan ancaman lebih berpengaruh, sehingga memerlukan langkah strategis 
pengelolaannya; 3). Hutan Kota

Waduk Sunter Utara dapat dikelola melalui strategi pengeloaan dengan urutan prioritas sebagai berikut : a. Rehabilitasi ekosistem, b. Kolaborasi pengelolaan, c. Perlindungan ekosistem, d. Sosialisasi eksistensi hutan kota, e. Pendidikan lingkungan dan penegakan hukum, f. Pengamanan hutan kota, g. Pemetaan zonasi pengelolaan.

\section{DAFTAR PUSTAKA}

Abbas R. Mekanisme Perencanaan Partisipasi Stakeholder Taman Nasional Gunung Rinjani [disertasi]. Bogor(ID). Institut Pertanian Bogor. 2005.

Al-Amin, Mufham. Manajemen Pengawasan. Jakarta : Kalam Indonesia. 2006

Crosby BL. Stakeholder Analysis: A vital tool for strategic managers, Technical Notes. 1992. [Internet]. [diunduh 2016 Desember 5]. Tersedia pada: http://pdf.usaid.gov/pdf_docs/pn abr482.pdf

Dharma, Agus. Manajemen Supervisi. Jakarta : Raja Grafindo Persada. 2001. Dreader and Anthony. Management Control System. Harvard University. Rich Inc. 1980.

E Saifuddin, Sarief. Konservasi Tanah dan Air. Bandung : Pustaka Buana. 1985.

Fayol, Hendri, dikutip langsung oleh Agarwal, S, K. Eco-informatics : Enviromental Management :
New Concepts. New Delhi. India : APH Publishing. 2002.

Golder B, WWF-US, Gawler M, ARTEMIS Service. CrossCutting Tool Stakeholder Analysis. 2005 [Internet]. [diunduh 2016 November 20]. Tersedia pada http://www.odi.urg.uk/sites/odi. urg.uk/files/odi-assets/ publications-opinionfiles/192.pdf

Hovland I. Successful Communication A Toolkit for Researchers and Civil Society Organisations. Research and Policy in Development ProgrammeOverseas Development Institute. 2005. [Internet]. [diunduh 2016 Desember 1]. Tersedia pada : http://www.odi.org.uk/sites/ odi.org.uk/files/odiassets/publications-opinionfiles/192.pdf

K, E, S Manik. Pengelolaan Lingkungan Hidup. Jakarta : Djambatan. 2003.

Laboratorium Perencanaan Lanskap Departemen Arsitektur Lanskap Fakultas Pertanian IPB. Ruang Terbuka Hijaun Wilayah Perkotaan. Jakarta : Departemen PU.2005.

Lubis, Mochtar. Melestarikan Hutan Tropika. Jakarta : Yayasan Obor. 1992.

M, Manulang. Dasar - Dasar Manajemen. Yogyakarta : Gajah Mada University Press. 2005.

Monde, $\mathrm{R}$ Wayke and Share $\mathrm{R}$. Premeaux. Management Concepts, Practices and Skill. Boston : Printice Hall International, Inc. 1998. 
Purnomohadi, Ning, et al. Ruang Terbuka Hijau sebagai Unsur Utama Tata Ruang Kota. Dirjen Penataan Ruang. Departemen PU. 2006.

Race D, Millar J. Training Manual: Social and community dimensions of ACIAR Projects. 2006. [diunduh 2016 Desember 15]. Tersedia pada : http://aciar.gov.au/files/node/73 32/Social.pdf

Rangkuti F. Analisis SWOT Teknik Membedah Kasus Bisnis. Jakarta (ID); PT.Gramedia Pustaka Utama. 1997.

Ramly, Nadjamudin. Membangun Lingkungan Hidup yang Harmoni dan Berperadaban. Jakarta : Grafindo. 2005.

Sarkis J. Quantitative Models for Performance Measurement Systems Altenate Considerations (Quantitative Strategic Planniing Matrix/ QSPM). International Journal of Production Economics. 2003.
Soedjadi, FX. Organization and Methods . Penunjang Berhasilnya Proses Manajemen. Jakarta : CV. H. Masagung. 1989.

Soerjani, M. Pembangunan dan Lingkungan. Jakarta : IPPL. 1997.

Soemarwoto, Otto. Indonesia dalam Kancah Isu Lingkungan Global. Jakarta : Gramedia. 1992.

Soegandhy, A. Penataan Ruang dalam Pengelolaan Lingkungan Hidup. Jakarta : Gramedia Pustaka Utama. 1999.

Terry, G, R dan L, W Rue. Dasar Dasar Manajemen, terjemahan G, A Ticoalu. Jakarta : Bumi Aksara. 2001.

Umar H. Manajemen Strategi in Action. Jakarta(ID): PT.Gramedia Pustaka Utama. 2008. 